\title{
Article \\ Effect of Photoconversion Coatings for Greenhouses on Electrical Signal-Induced Resistance to Heat Stress of Tomato Plants
}

\author{
Marina Grinberg ${ }^{1}\left(\mathbb{D}\right.$, Ekaterina Gromova ${ }^{1}$, Alyona Grishina ${ }^{1}$, Ekaterina Berezina ${ }^{2}$, Maria Ladeynova ${ }^{1}$, \\ Alexander V. Simakin ${ }^{3}$, Vladimir Sukhov ${ }^{1}\left(\mathbb{D}\right.$, Sergey V. Gudkov ${ }^{1,3}$ a and Vladimir Vodeneev ${ }^{1, *(\mathbb{D})}$ \\ 1 Department of Biophysics, Lobachevsky State University of Nizhny Novgorod, Gagarin St., 23, \\ 603950 Nizhny Novgorod, Russia; mag1355@yandex.ru (M.G.); kater333@inbox.ru (E.G.); \\ 79159532707@yandex.ru (A.G.); ladeynova.m@yandex.ru (M.L.); vssuh@mail.ru (V.S.); \\ S_makariy@rambler.ru (S.V.G.) \\ 2 Department of Biochemistry and Biotechnology, Lobachevsky State University of Nizhny Novgorod, \\ Gagarin St., 23, 603950 Nizhny Novgorod, Russia; berezina.kat@gmail.com \\ 3 Prokhorov General Physics Institute of the Russian Academy of Sciences, Vavilova St., 38, \\ 119991 Moscow, Russia; avsimakin@gmail.com \\ * Correspondence: v.vodeneev@mail.ru; Tel.: +7-910-388-3799
}

Citation: Grinberg, M.; Gromova, E.; Grishina, A.; Berezina, E.; Ladeynova, M.; Simakin, A.V.; Sukhov, V.; Gudkov, S.V.; Vodeneev, V. Effect of Photoconversion Coatings for Greenhouses on Electrical SignalInduced Resistance to Heat Stress of Tomato Plants. Plants 2022, 11, 229. https://doi.org/10.3390/ plants11020229

Academic Editor: Kent Burkey

Received: 11 December 2021

Accepted: 14 January 2022

Published: 17 January 2022

Publisher's Note: MDPI stays neutral with regard to jurisdictional claims in published maps and institutional affiliations.

Copyright: (C) 2022 by the authors. Licensee MDPI, Basel, Switzerland. This article is an open access article distributed under the terms and conditions of the Creative Commons Attribution (CC BY) license (https:// creativecommons.org/licenses/by/ $4.0 /)$.

\begin{abstract}
The use of photoconversion coatings is a promising approach to improving the quality of light when growing plants in greenhouses in low light conditions. In this work, we studied the effect of fluoropolymer coatings, which produce photoconversion of UV-A radiation and violet light into blue and red light, on the growth and resistance to heat stress of tomato plants (Solanum lycopersicum L.). The stimulating effect of the spectrum obtained as a result of photoconversion on plant growth and the activity of the photosynthesis process are shown. At the same time, the ability to withstand heat stress is reduced in plants grown under a photoconversion coating. Stress electrical signals, which normally increase resistance, in such plants have a much weaker protective effect on the photosynthetic apparatus. The observed effects are apparently explained by a decrease in the concentration of $\mathrm{H}_{2} \mathrm{O}_{2}$ in plants grown using photoconversion technologies, which leads to a shift in the development program towards increased productivity to the detriment of the protective function. Thus, when using photoconversion technologies in agricultural practice, it is necessary to pay increased attention to maintaining stable conditions during plant cultivation.
\end{abstract}

Keywords: photoconversion coatings; stress signals; photosynthesis; reactive oxygen species; resistance to environment stressors; Solanum lycopersicum

\section{Introduction}

Improving the efficiency of greenhouses is an urgent problem in agriculture. In temperate and polar latitudes, one of the most serious problems is insufficient illumination, in particular at wavelengths used in the course of photosynthetic reactions. This problem can be solved by active backlighting using LEDs or other light sources [1-6]. However, this approach requires high economic and energy costs, which leads to an increase in carbon footprint [7]. Another approach is passive spectrum correction using films and coatings. To date, research on photoactive coatings for greenhouses has focused mainly on three aspects: protection against near-infrared radiation, protection against UV radiation and the conversion of photons of photosynthetically inactive spectral ranges into blue and red light [8-11]. The latter approach seems especially promising, since it demonstrates a significant stimulating effect on morphometric parameters and the activity of physiological processes in various plant species [10-15].

In addition to productivity for plants, resistance to various stressful influences is of great importance. In greenhouse conditions, the most significant damaging factors for 
plants are high temperatures on sunny days and various pathogenic organisms. For the formation of complex resistance to stressors at the level of the whole plant, distant stress signals are important [16-18]. As a rule, the signal is generated in the most vulnerable or sensitive zone of the plant, for example, in the upper young leaves, and then spreads throughout the body, modulating intracellular signaling pathways and the activity of physiological processes, which leads to an increase in resistance $[17,18]$. Distant stress signals, depending on the nature, are subdivided into several types, each of which is induced by its own set of stressors and has a characteristic speed of propagation and scale of coverage. Hydraulic, chemical and electrical signals are distinguished $[16,19,20]$. Electrical signals (ES), representing a wave of changes in the electrical potential on cell membranes, are of particular interest under the action of rapidly growing stressors, to which it is required to quickly increase resistance at the level of the whole plant. ROS and $\mathrm{Ca}^{2+}$ signaling systems are involved in the generation and propagation of ES. Entering cells through, presumably, ROS-activated cation channels, $\mathrm{Ca}^{2+}$ causes the opening of anion channels and inactivation of proton ATPase; as a result of which an electrical signal develops [16,20]. Such signals are induced by a wide range of stimuli, including changes in temperature, humidity, excessive lighting and attack by leaf-eating insects [21]. Spreading through the plant at a rate of the order of $\mathrm{mm} \times \mathrm{s}^{-1}$, ES cause functional responses, first of all, a temporary inhibition of the light-driven and light-independent reactions of photosynthesis and transpiration, which allows plants to survive an unfavorable period with minimal damage [22,23]. It should be noted that the $\mathrm{ROS}$ and $\mathrm{Ca}^{2+}$ systems participating in longdistance signaling are modulated by lighting conditions [21,24,25].

In our previous works $[10,14]$, we showed that fluoropolymer coatings, which produce photoconversion of UV-A radiation and violet light into blue and red light, stimulate the growth, development and yield of plants but inhibit heat-induced electrical signals. In this work, we study the effect of these photoconversion coatings on the electrical signal-induced resistance of tomato plants to heat stress.

\section{Materials and Methods}

\subsection{Growing Plants under Photoconversion Coating}

The studies were carried out on 5-week-old tomato plants (Solanum lycopersicum L.), variety "Komnatnyj syurpriz" (undersized, early maturing). The plants were grown in a vegetation room under a 16-h light period at a constant air temperature of $23{ }^{\circ} \mathrm{C}$ and a relative humidity of about $50 \%$. Plants were grown in individual pots in growing media (peat $96 \%$, dolomite flour $4 \%$; $\mathrm{pH}=5.8$ ), watering was carried out two times a week.

A combination of incandescent (95 W; Brest Electric Lamp Plant, Brest, Belarus) and UV lamps (Litarc Lighting and Electronic Ltd., Shenzhen, China; maximum emission at $365 \mathrm{~nm}$ ) was used as a light source to simulate solar light. Photoconversion coatings were placed between the lamps and plants. For the photoconversion coating, we used fluoropolymer films containing gold nanoparticles and $\mathrm{Cd}_{(1-\mathrm{x})} \mathrm{Zn}_{(\mathrm{x})}$ Se quantum dots [10], located between plants and light sources. Films produce photoconversion of UV-A radiation and violet light into blue (photoluminescence maximum $450 \mathrm{~nm}$ ) and red light (photoluminescence maximum $630 \mathrm{~nm}$ ). When using a light-converting composite film, we have light close to the emission spectrum of a blackbody with the imposition of "blue" and "red" components on it (Figure 1). The photoluminescence spectrum of the photoconversion coating obtained using a broader spectrum xenon reference light source is shown in Figure S1 in the Supplementary Materials. The photoluminescence maxima of photoconversion films obtained upon irradiation with a combination of light sources used in the experiment correspond to the maxima obtained upon irradiation with a reference source (Figures 1 and S1). The light intensity at the plant leaf level was $247 \mu \mathrm{mol}$ photons $\mathrm{m}^{-2} \mathrm{~s}^{-1}$. Control plants were grown under similar conditions using a luminous flux equalization filter (fluoropolymer films without photoconverting components) instead of a photoconversion coating. The spectrum of the light sources after the neutral filter corresponded to the spectrum of the light sources itself. The proportion of UV-A radiation (measured from 340 to $400 \mathrm{~nm}$ ) 
was $7.8 \%$ in the total spectrum (from 340 to $750 \mathrm{~nm}$ ), which is close to the distribution of light energy in the spectrum of solar radiation (UV 6\%, visible light 52\% and IR 42\%) [26]. Spectrum parameters were recorded using an Ocean Insight FLAME spectrometer (Ocean Insight, Largo, FL, USA) and a PM100D radiation power/energy meter complex (Thorlabs, Newton, NJ, USA).
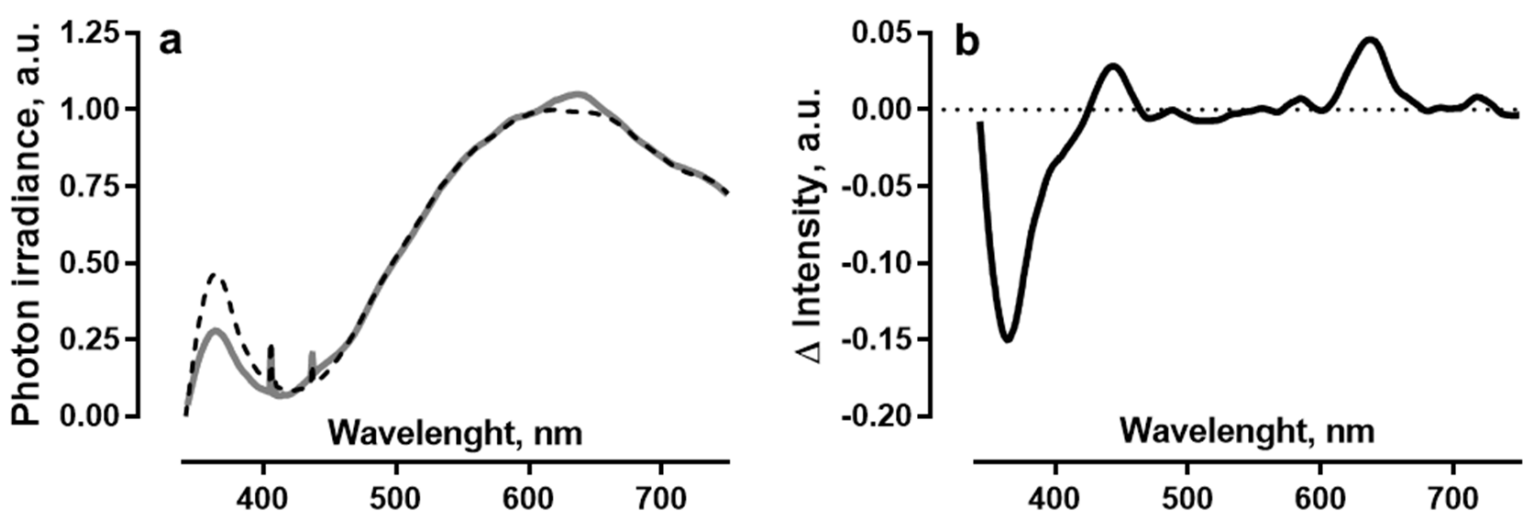

Figure 1. (a) Normalized photoluminescence spectrum of a fluoropolymer film containing fluorophores and gold nanoparticles (solid line) and without photoconverting components (dotted line); (b) the difference between the intensities of the spectra of a fluoropolymer photoconversion film and a fluoropolymer equalizing filter.

\subsection{Methods}

\subsubsection{Measurement of Morphometric Indicators}

The growth rate of plants was estimated from the leaf area. The analysis of the total leaf area of individual plants was carried out from photographs using a macro based on the ImageJ program. Photographing was carried out every 3-5 days throughout the entire period of plant cultivation.

\subsubsection{Measurement of the Parameters of Photosynthesis and Transpiration}

To register the parameters of photosynthesis and transpiration, a GFS-3000 infrared gas analyzer and a Dual-PAM-100 PAM fluorometer with a Dual-PAM gas-exchange Cuvette 3010-Dual measuring head (Heinz Walz GmbH, Pfullingen, Germany) were used. The calculation of the efficiency of PSII photochemistry $\left(\mathrm{F}_{\mathrm{v}} / \mathrm{F}_{\mathrm{m}}\right)$, the quantum yield of photochemical reactions of photosystem I $\left(\Phi_{\text {PSI }}\right)$ and photosystem II $\left(\Phi_{\text {PSII }}\right)$ and non-photochemical quenching of fluorescence (NPQ) were carried out in accordance with $[27,28]$ :

- $\quad \mathrm{F}_{\mathrm{m}}$ is the maximum yield of fluorescence after dark adaptation;

- $\mathrm{F}_{\mathrm{v}}=\mathrm{F}_{\mathrm{m}}-\mathrm{F}_{0}$, where $\mathrm{F}_{0}$ is level of fluorescence without light and after dark adaptation;

- $\Phi_{\mathrm{PSI}}=\left(\mathrm{P}_{\mathrm{m}}{ }^{\prime}-\mathrm{P}\right) / \mathrm{P}_{\mathrm{m}}$, where $\mathrm{P}_{\mathrm{m}}$ is the maximum change in $\mathrm{P}_{700}$ signal of photosystem I, which reflects the complete oxidation of $\mathrm{P}_{700}, \mathrm{P}_{\mathrm{m}}{ }^{\prime}$ is the maximum change in $\mathrm{P}_{700}$ signal in the light and $\mathrm{P}$ is the current level of $\mathrm{P}_{700}$ signal;

- $\quad \Phi_{\mathrm{PSII}}=\left(\mathrm{F}_{\mathrm{m}}{ }^{\prime}-\mathrm{F}_{\mathrm{t}}\right) / \mathrm{F}_{\mathrm{m}}{ }^{\prime}$, where $\mathrm{F}_{\mathrm{m}}{ }^{\prime}$ is the maximum yield of fluorescence in the light and $F_{t}$ is the steady-state value of fluorescence immediately prior to the flash;

- $\quad \mathrm{NPQ}=\left(\mathrm{F}_{\mathrm{m}}-\mathrm{F}_{\mathrm{m}}{ }^{\prime}\right) / \mathrm{F}_{\mathrm{m}}{ }^{\prime}$.

To maintain photosynthesis (actinic light), illumination with a wavelength of $460 \mathrm{~nm}$ was used; the photon flux density was $239 \mu \mathrm{mol} \times \mathrm{m}^{-2} \times \mathrm{s}^{-1}$. For saturating light pulses, illumination at a wavelength of $635 \mathrm{~nm}$ with a photon flux density of $10,000 \mu \mathrm{mol} \mathrm{m} \mathrm{m}^{-2} \times \mathrm{s}^{-1}$ was used. The duration of saturating light pulses was $300 \mathrm{~ms}$ and the interval between flashes was $10 \mathrm{~s}$. The concentration of $\mathrm{CO}_{2}$ in the measuring cell was maintained at $360 \mu \mathrm{mol} \times \mathrm{mol}^{-1}$, temperature $23{ }^{\circ} \mathrm{C}$, relative humidity $60 \%$. The area of the investigated area of the leaf was $1.3 \mathrm{~cm}^{2}$. Measurements were made on the second adult leaf from the top. The recording of the dark parameters of assimilation and transpiration began 
$10 \mathrm{~min}$ after plant fixation and continued for $15 \mathrm{~min}$. Then, together with the gas exchange, registration of the light-driven reactions of photosynthesis began, which lasted $20 \mathrm{~min}$.

\subsubsection{Registration of Long-Distance Electrical Signals}

An electrical signal was induced by gradual heating of the tip of the upper adult leaf $\left(2 \mathrm{~cm}^{2}\right)$ in a cuvette with water heated to $55^{\circ} \mathrm{C}$. Electric potentials were recorded from the plant surface using $\mathrm{Ag}^{+} / \mathrm{AgCl}$ macroelectrodes. The measuring electrode was located on the petiole of the heated leaf. The contact of the electrode with the leaf was carried out through a thread soaked in a standard solution $(1 \mathrm{mM} \mathrm{KCl}, 0.5 \mathrm{mM} \mathrm{CaCl}$ and $0.1 \mathrm{mM} \mathrm{NaCl})$. The reference electrode was located in the soil. The potential difference was measured by a multichannel system for measuring biopotentials, Multitest IPL-113 (Semico, Russia), and processed on a PC using the Param 2 program. The adaptation between plant fixation and signal induction was $1 \mathrm{~h}$.

\subsubsection{Measurement of Resistance to Heat Stress Induced by Electrical Signals}

Before placing the plants in stressful conditions, the level of photosynthesis in them at rest was recorded and ES was induced. Heat stress was caused $45 \mathrm{~min}$ after ES by total heating of a vessel with plants in a TS- $1 / 80$ SPU thermostat (Smolensk SKTB SPU, Smolensk, Russia) for $45 \mathrm{~min}$ at a temperature of $46^{\circ} \mathrm{C}$. The plant resistance to heat stress was assessed by the level of residual photosynthesis $1 \mathrm{~h}$ after the end of heating.

\subsubsection{Determination of $\mathrm{H}_{2} \mathrm{O}_{2}$ Content}

The change in hydrogen peroxide $\left(\mathrm{H}_{2} \mathrm{O}_{2}\right)$ concentration in tomato leaves was analyzed using 3,3'-diaminobenzidine (DAB) staining. Intact middle-aged leaves were immersed in a staining solution $\left(1 \mathrm{mg} / \mathrm{mL} \mathrm{DAB}, 10 \mathrm{mM} \mathrm{KH}_{2} \mathrm{PO}_{4}\right.$ and $0.05 \% v / v$ Tween 20$)$ and infiltrated in a vacuum desiccator at $-50 \mathrm{kPa}$ for $1.5 \mathrm{~min} 3$ times with pauses for $3 \mathrm{~min}$. Incubation was carried out for $4 \mathrm{~h}$ in the dark on an OS-20 orbital shaker (BioSan, Riga, Latvia) at $100 \mathrm{rpm}$. The leaves were then decolorized with $96 \%$ ethanol by heating to $80^{\circ} \mathrm{C}$. Leaves were photographed using a stereomicroscope (Meiji Techno, Chikumazawa, Japan) and a digital camera. Image processing was performed in the ImageJ program. The color intensity was determined by the region of interest of a fixed value from each leaf.

\subsubsection{Statistics}

The results were obtained on plants grown in two separate series: the first series from June to August and the second from August to October 2021. The number of plants in each series was 18-20. Each type of experiment comprised 6-12 repetitions; every replicate was performed on a separate plant. The mean and standard error of the mean were calculated and the normal data distribution was confirmed for all the experiments; the significance of differences was determined by the Student's $t$-test. The results also show typical records of the parameters of photosynthesis and transpiration at rest and after propagation of an electrical signal, obtained in control plants.

\section{Results}

\subsection{Effect of Photoconversion Coatings on Morphometric Parameters of Plants}

Cultivation under photoconversion coatings stimulates the growth of leaves of tomato plants (Figure 2). Differences in leaf area begin to appear in the third week-with the development of the first true (not cotyledonous) leaf. In the following weeks, differences in leaf area increase. On the 36th day, the leaf area of the control plants is $33 \pm 4 \mathrm{~cm}^{2}$ and the leaf area of plants grown under photoconversion coatings is $63 \pm 11 \mathrm{~cm}^{2}$. 

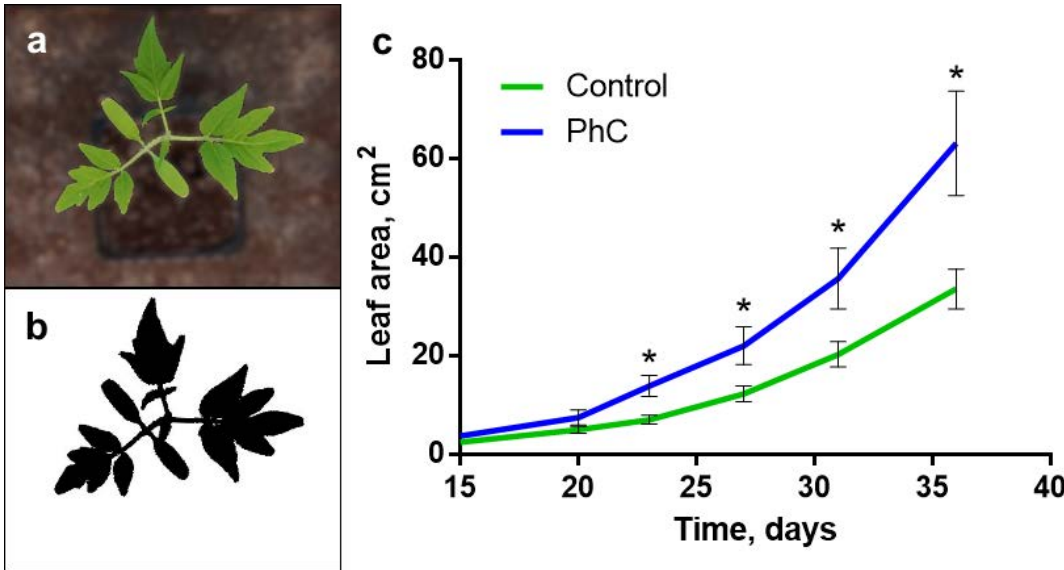

Figure 2. Influence of photoconversion coatings on the leaf area of tomato plants: $(\mathbf{a}, \mathbf{b})$ a photograph of a control tomato plant and a "mask" for calculating the leaf area using the ImageJ macro; (c) dynamics of changes in the leaf area of control plants and plants grown using the photoconversion coating $(\mathrm{PhC})$. $^{*}: p<0.05$.

\subsection{Effect of Photoconversion Coatings on Photosynthetic Activity and Transpiration Rate}

The effect of growing under a photoconversion coating on the physiological processes of tomato seedlings was assessed by the parameters of the light-driven reactions of photosynthesis (efficiency of PSII photochemistry $\left(\mathrm{F}_{\mathrm{v}} / \mathrm{F}_{\mathrm{m}}\right)$, quantum yield of photochemical reactions of photosystem I ( $\left.\Phi_{\mathrm{PSI}}\right)$ and photosystem II ( $\left.\Phi_{\mathrm{PSII}}\right)$ and non-photochemical quenching of fluorescence (NPQ)) and indicators of gas exchange- the activity of assimilation of $\mathrm{CO}_{2}(\mathrm{~A})$ and the intensity of transpiration (E) in the light. In tomato seedlings, the reaction to the switching on of light for all the studied parameters is a gradual transition from the dark level to the light level, reaching a plateau in about 20-30 min (Figure 3a,e).
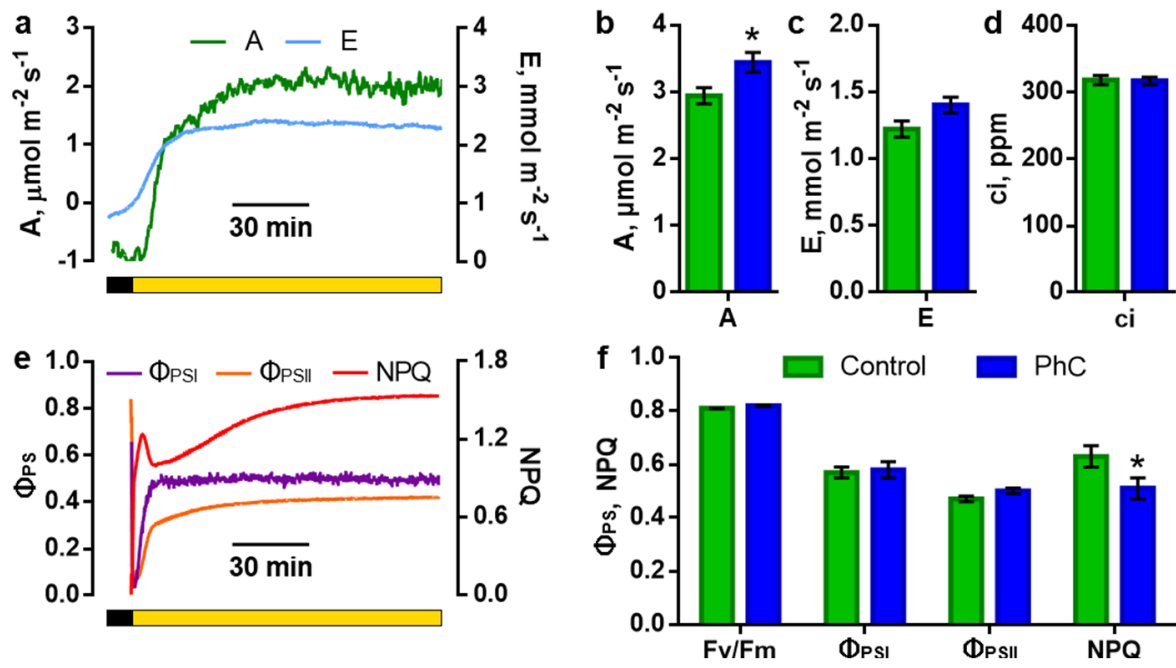

Figure 3. Influence of a photoconversion coating on the activity of photosynthesis and the intensity of transpiration of tomato plants: (a) a typical record of the responses of assimilation and transpiration of a control tomato plant to the switching on of the light; $(\mathbf{b}-\mathbf{d})$ the effect of the photoconversion coating on the level of assimilation, the intensity of transpiration and intercellular $\mathrm{CO}_{2}$ concentration; (e) a typical record of the light-driven reactions of photosynthesis of a control tomato plant to light switching on; (f) the effect of the photoconversion coating on the light-driven reactions of photosynthesis. A: assimilation of $\mathrm{CO}_{2}$; E: transpiration; ci: intercellular $\mathrm{CO}_{2}$ concentration; $\mathrm{F}_{\mathrm{v}} / \mathrm{F}_{\mathrm{m}}$ : efficiency of PSII photochemistry; $\Phi_{\mathrm{PSI}}$ and $\Phi_{\mathrm{PSII}}$ : quantum yield of photochemical reactions of photosystems I and II; NPQ: non-photochemical quenching of fluorescence; PhC: photoconversion. *: $p<0.05$. 
Activation of photosynthesis was registered in tomato plants grown under a photoconversion coating. The level of the integral indicator of photosynthesis- $\mathrm{CO}_{2}$ assimilationsignificantly increased from $2.94 \pm 0.12$ to $3.44 \pm 0.15 \mu \mathrm{mol} \times \mathrm{m}^{-2} \times \mathrm{s}^{-1}$ (Figure $3 \mathrm{~b}$ ). In this case, the intensity of transpiration did not undergo statistically significant changes and was $1.22 \pm 0.06 \mathrm{mmol} \times \mathrm{m}^{-2} \times \mathrm{s}^{-1}$ in control plants and $1.40 \pm 0.06 \mathrm{mmol} \times \mathrm{m}^{-2} \times \mathrm{s}^{-1}$ in those grown under a photoconversion coating (Figure 3c). Intercellular $\mathrm{CO}_{2}$ concentration (ci) also showed no dependence on the photoconversion coating: $318 \pm 7$ ppm in control plants and $317 \pm 6$ in plants grown using photoconversion coatings (Figure $3 \mathrm{~d}$ ). Analysis of the light-driven reactions showed a decrease in the NPQ level from $0.63 \pm 0.04$ to $0.51 \pm 0.04$ in plants grown using photoconversion coatings (Figure $3 f$ ). Indicators $F_{\mathrm{v}} / F_{m}$ and $\Phi_{\text {PSII }}$ do not differ from control.

\subsection{Effect of Photoconversion Coatings on Electrical Signal-Induced Heat Stress Tolerance}

To analyze the resistance of plants grown under the photoconversion coating to stressors, tomato seedlings were exposed to elevated temperatures. The effect of heat stress (HS) was assessed by the residual activity of photosynthesis (Figure 4).
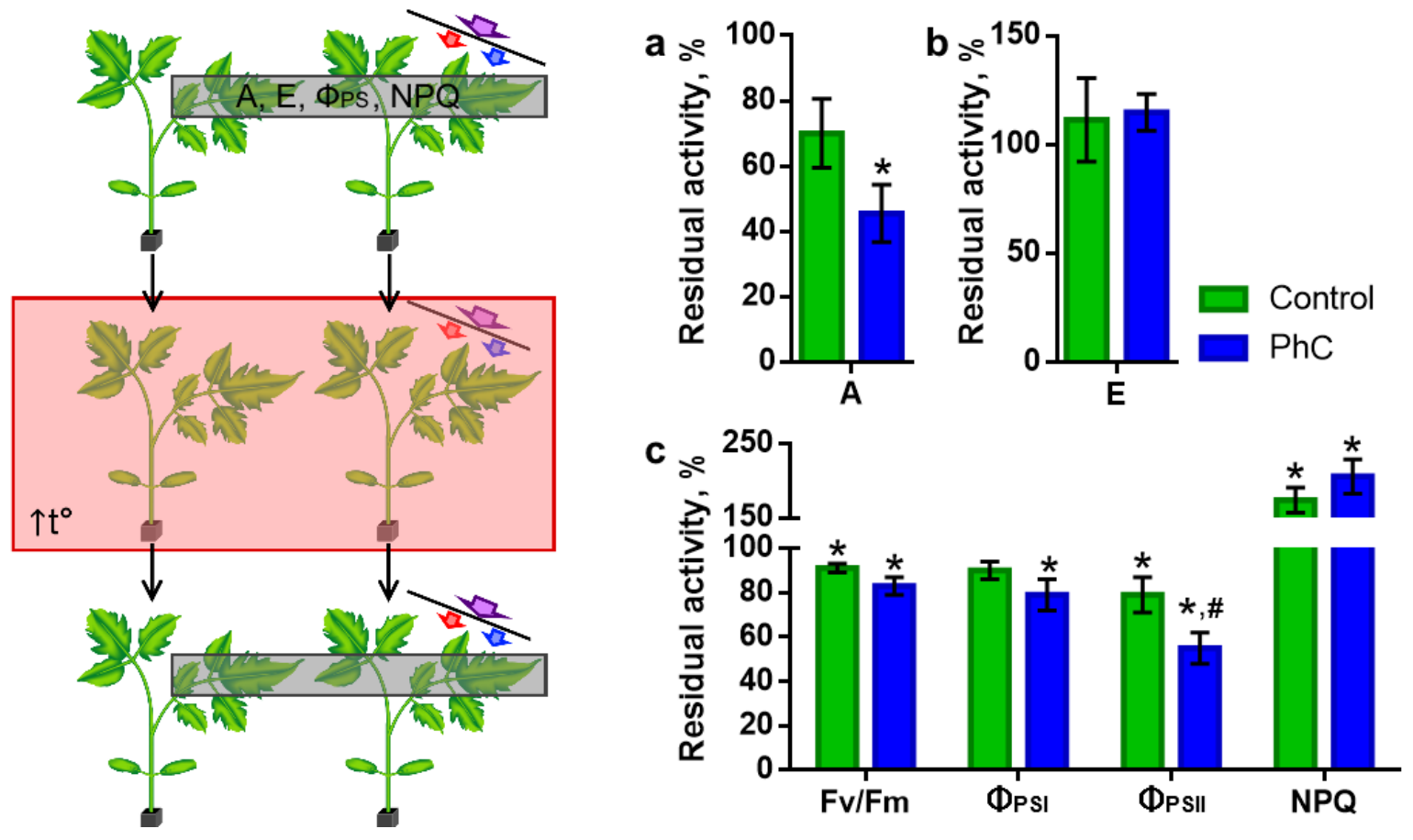

Figure 4. Effect of a photoconversion coating on the resistance of tomato plants to heat stress, which was determined by the residual activity of physiological processes after heating: (a) residual activity of assimilation; (b) residual activity of transpiration; (c) residual activity of light-driven photosynthesis reactions. Residual activity is expressed in percentages, where $100 \%$ corresponds to the level before HS. The measurement scheme is shown on the left. Photosynthesis levels were first recorded (gray rectangle in the scheme); then, plants were subjected to heat stress for $45 \mathrm{~min}$ at a temperature of $46{ }^{\circ} \mathrm{C}$ (red rectangle in the scheme). The residual levels of photosynthesis were recorded $1 \mathrm{~h}$ after heat stress. A: assimilation of $\mathrm{CO}_{2} ; \mathrm{E}$ : transpiration; $\mathrm{F}_{\mathrm{v}} / \mathrm{F}_{\mathrm{m}}$ : efficiency of PSII photochemistry; $\Phi_{\mathrm{PSI}}$ and $\Phi_{\text {PSII }}:$ quantum yield of photochemical reactions of photosystems I and II; NPQ: non-photochemical quenching of fluorescence; PhC: photoconversion. *: the difference between "after HS" and "before HS" is significant, $p<0.05$; \#: the difference between "control" and "photoconversion" is significant, $p<0.05$.

After the action of heat stress, both in control plants and those grown using a photoconversion coating, a significant suppression of photosynthetic processes was observed (Figure 4). An hour after the end of heating in the control, the residual level of $F_{\mathrm{v}} / \mathrm{F}_{\mathrm{m}}$ was 
$91 \pm 2 \%$, $\Phi_{\text {PSII }}$ was $90 \pm 4 \%$, $\Phi_{\text {PSI }}$ was $79 \pm 8 \%$, NPQ was $174 \pm 2 \%$ and A was $70 \pm 11 \%$. In this case, the intensity of transpiration did not significantly differ from the control and was $111 \pm 19 \%$. For plants grown under photoconversion films, the residual level of photosynthetic parameters was $83 \pm 4 \%, 79 \pm 7 \%, 55 \pm 7 \%, 206 \pm 23 \%$ and $45 \pm 9 \%$, respectively. The intensity of transpiration was $115 \pm 8 \%$. Thus, plants grown using photoconversion technologies exhibit lower resistance to heat stress, which is indicated by a tendency towards a decrease in all photosynthetic parameters and a significantly lower level of residual $\Phi_{\text {PSII }}$ after heating.

An electrical signal induced by a local stimulus is a depolarization wave propagating from the stimulation zone with an amplitude of several tens of $\mathrm{mV}$ (Figure 5a). In tomato plants, an electrical signal induced by local heating leads to a transient change in the activity of both the light-driven and light-independent reactions of photosynthesis in the neighboring leaf: the level of A and $\Phi_{\text {PSI }}$ decreases and the level of NPQ increases (Figure $\left.5 b, c\right)$. The intensity of transpiration decreases as a result of signal transmission (Figure 5b).
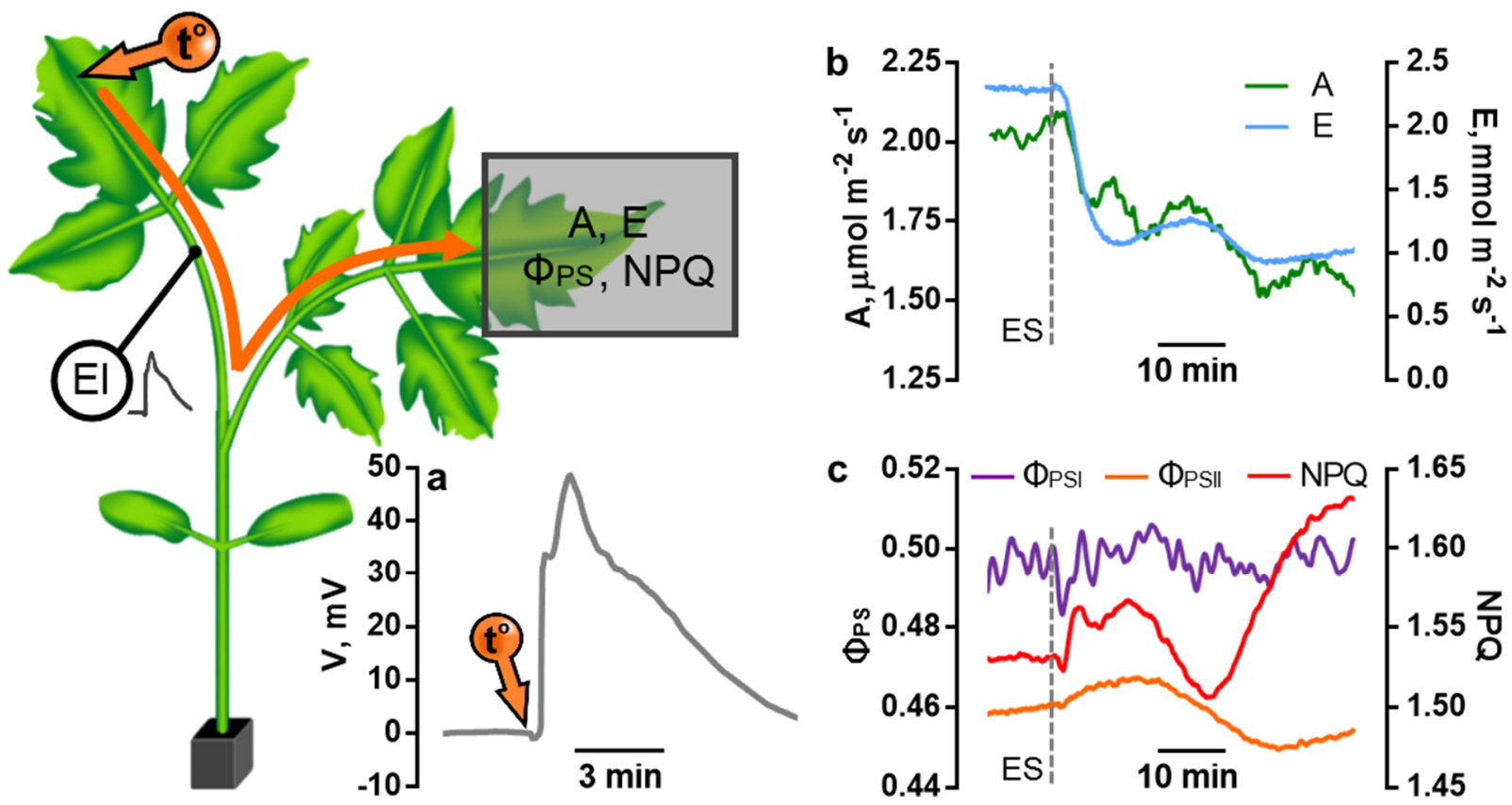

Figure 5. Local heating-induced electrical signal in a tomato plant: (a) Measurement scheme and typical record of an electrical signal of a control tomato plant. The electrical signal was induced by gradual heating of the tip of the upper adult leaf in a cuvette with water heated to $55^{\circ} \mathrm{C}$. Electric potentials were recorded with an electrode (El) on the petiole of the heated leaf. Photosynthesis parameters were recorded in the second from the top adult leaf. (b) The responses of the lightdriven reactions of photosynthesis evoked by an electrical signal of a control tomato plant. (c) The responses of assimilation and transpiration evoked by an electrical signal of a control tomato plant. A: $\mathrm{CO}_{2}$ assimilation; $\mathrm{E}$ : transpiration; $\mathrm{F}_{\mathrm{v}} / \mathrm{F}_{\mathrm{m}}$ : potential quantum yield; $\Phi_{\mathrm{PSI}}$ and $\Phi_{\mathrm{PSII}}$ : quantum yield of photochemical reactions of photosystems I and II; NPQ: non-photochemical quenching of fluorescence.

Electrical signals and the functional responses elicited by them contribute to an increase in plant resistance to stressors, including heat stress (Figure 6). 


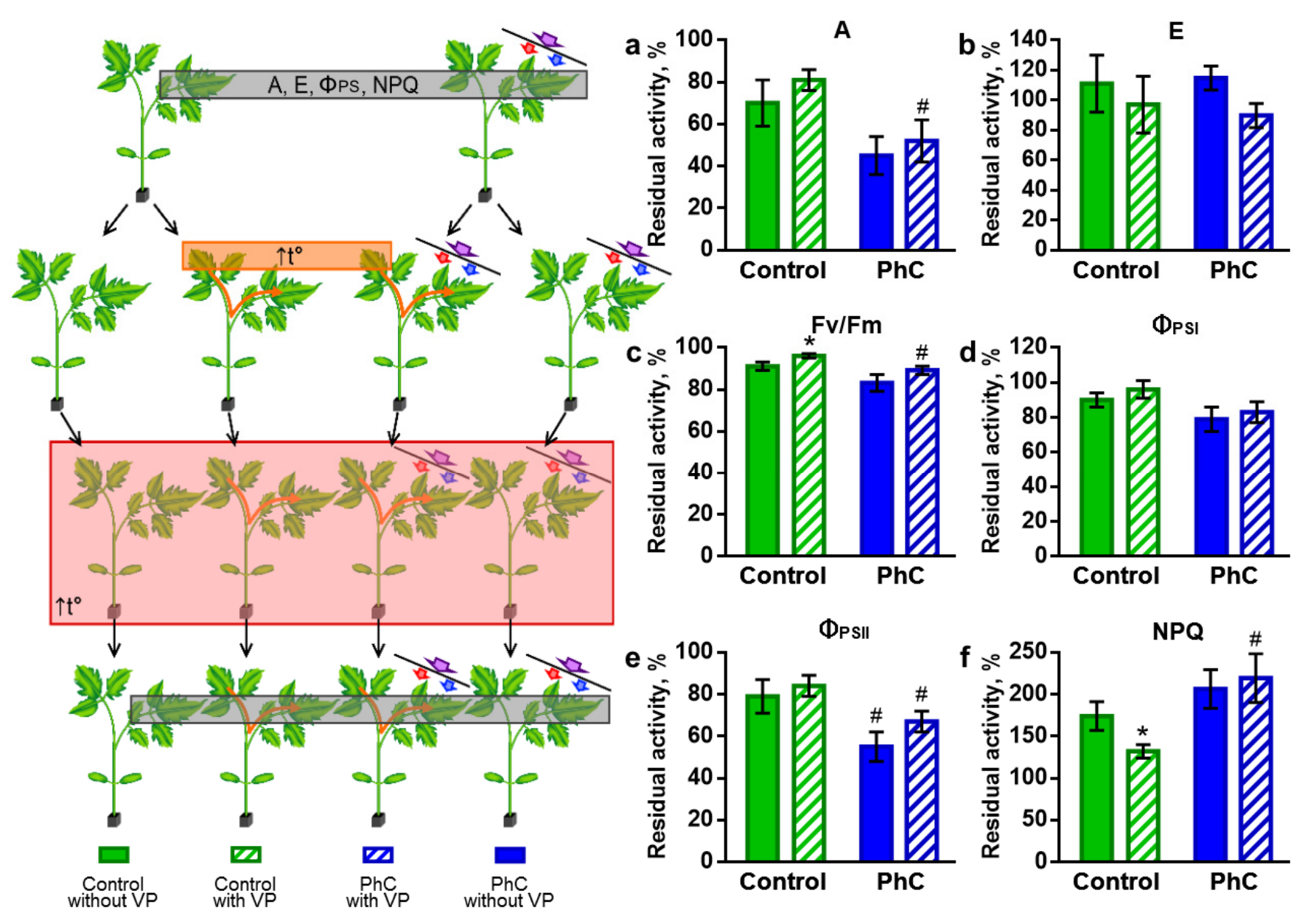

Figure 6. Influence of photoconversion coatings on electrical signal-induced resistance of tomato plants to heat stress, which was determined by the residual activity of physiological processes after heating: (a) residual activity of assimilation; (b) residual activity of transpiration; (c-f) residual activity of light-driven photosynthesis reactions. Residual activity is expressed in percentages, where $100 \%$ corresponds to the level before HS. The measurement scheme is shown on the left. Photosynthesis levels were first recorded (gray rectangle in the scheme); then, in half of the plants, ES was induced by short-term heating of the top leaf (orange rectangle and arrow in the scheme); after $45 \mathrm{~min}$, all the plants were subjected to heat stress for $45 \mathrm{~min}$ at a temperature of $46{ }^{\circ} \mathrm{C}$ (pink rectangle in the scheme). The residual levels of photosynthesis were recorded $1 \mathrm{~h}$ after heat stress. A: assimilation of $\mathrm{CO}_{2} ; \mathrm{E}$ : transpiration; $\mathrm{F}_{\mathrm{v}} / \mathrm{F}_{\mathrm{m}}$ : efficiency of PSII photochemistry; $\Phi_{\mathrm{PSI}}$ and $\Phi_{\text {PSII }}$ : quantum yield of photochemical reactions of photosystems I and II; NPQ: non-photochemical quenching of fluorescence; PhC: photoconversion. *: the difference between "without ES" and "with ES" is significant, $p<0.05$; \#: the difference between "control" and "photoconversion" is significant, $p<0.05$.

In tomato plants, in which heat-induced ES occurs before heat stress, higher levels of residual parameters of photosynthesis were recorded (Figure 6). A significant increase in the $\mathrm{F}_{\mathrm{v}} / \mathrm{F}_{\mathrm{m}}$ level was shown (96 $\pm 1 \%$ after ES instead of $91 \pm 2 \%$ in the control) and a decrease in the NPQ level was observed (132 $\pm 8 \%$ after ES instead of $174 \pm 17 \%$ in the control). ES had no effect on the level of transpiration. In plants grown using a photoconversion coating, there was only a tendency to an increase in the residual levels of indicators in the presence of ES, and no statistically significant differences were found. As a result, such plants after heat stress demonstrated significantly lower levels for a number of key parameters in comparison with the control with $\mathrm{ES}\left(\mathrm{F}_{\mathrm{V}} / \mathrm{F}_{\mathrm{m}}\right.$ was $96 \pm 1 \%$ in the control and $89 \pm 2 \%$ under the films, $\Phi_{\text {PSII }}$ was $84 \pm 5 \%$ in control and $67 \pm 5 \%$ under the 
films, NPQ was $132 \pm 8 \%$ in the control and $219 \pm 29 \%$ under the films, A was $81 \pm 5 \%$ in the control and $52 \pm 10 \%$ under the films). In general, stress ESs in plants grown under photoconversion films have reduced protective properties with respect to photosynthesis under heat stress.

\subsection{Effect of Photoconversion Coatings on the $\mathrm{H}_{2} \mathrm{O}_{2}$ Content in Plant Leaves}

The reactive oxygen species (ROS) content was estimated by the most long-lived form, hydrogen peroxide. The amount of $\mathrm{H}_{2} \mathrm{O}_{2}$ was determined by DAB staining (Figure $7 \mathrm{a}, \mathrm{b}$ ). A decrease in the level of $\mathrm{H}_{2} \mathrm{O}_{2}$ was found in plants grown under photoconversion films. In the leaves of such plants, the content of $\mathrm{H}_{2} \mathrm{O}_{2}$ was lower than the control values by $17 \pm 3 \%$ (Figure $7 \mathrm{c}$ ).
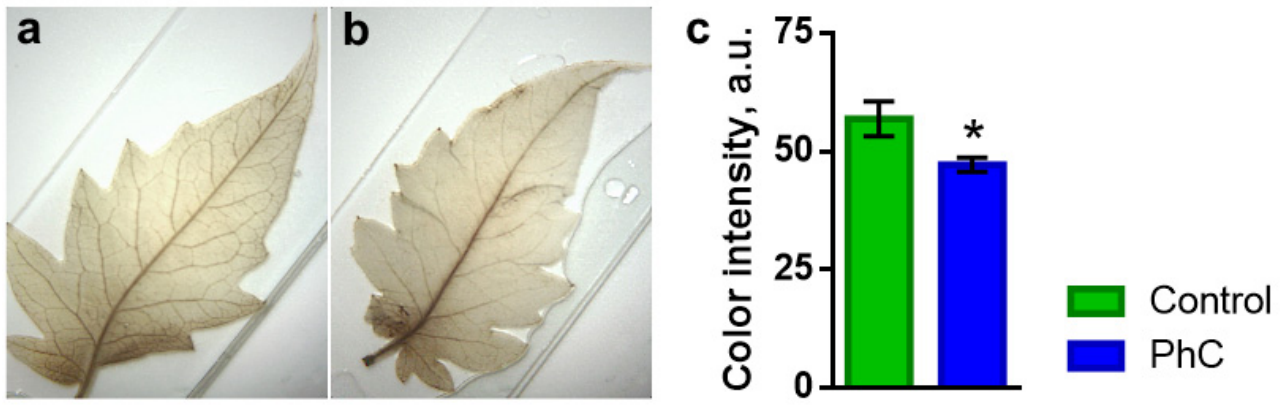

Figure 7. Influence of photoconversion coatings on the content of $\mathrm{H}_{2} \mathrm{O}_{2}$ in the leaves of tomato plants: $(\mathbf{a}, \mathbf{b})$ photograph of leaves of a control tomato plant and a plant grown under a photoconversion coating, stained with DAB; (c) relative content of $\mathrm{H}_{2} \mathrm{O}_{2}$ in the leaves of control plants and plants grown under a photoconversion coating. ${ }^{*}: p<0.05$.

\section{Discussion}

Plants were grown under photoconversion films, which produce photoconversion of UV-A radiation and violet light into blue and red light [10]. The use of a photoconversion coating increases the size of the leaves (Figure 2). The reason for this may be the experimentally observed stimulation of the process of photosynthesis. It was shown that in plants grown under a photoconversion coating, there is an increase in $\mathrm{CO}_{2}$ assimilation-an integral indicator of photosynthesis activity (Figure 3b). Assimilation, as a rule, is closely related to the level of transpiration: transpiration reflects the degree of stomatal openness and, consequently, the availability of $\mathrm{CO}_{2}$ for cells. In plants grown under a photoconversion coating, assimilation increases against the background of constant transpiration and intercellular $\mathrm{CO}_{2}$ concentration (Figure $3 \mathrm{~b}-\mathrm{d}$ ). This indicates the predominant regulation at the level of the activity of photosynthetic processes, rather than the availability of $\mathrm{CO}_{2}$. This is confirmed by the stimulation of the light-driven reactions of photosynthesis, found when using a photoconversion coating. Such stimulation is evidenced by an increase in the $\Phi_{\text {PSII }}$ level, which reflects the quantum yield of Photosystem 2, and a decrease in the NPQ level, reflecting non-photochemical quenching of fluorescence (Figure 3f).

Photoconversion coatings can affect photosynthesis in two ways: (1) by increasing photosynthetically active radiation (PAR) and (2) by reducing the UV component in the spectrum. The coatings used in this work have photoluminescence maxima at 450 and $630 \mathrm{~nm}$, which quite well correspond to the absorption maxima of tomato plants, located in the region of 440 and $675 \mathrm{~nm}$ [29]. Stimulating photosynthesis by increasing the proportion of light in the blue and red regions of the spectrum has been shown in a large number of works $[1-6,10,11,14]$. Such stimulation can be caused both by a direct increase in the amount of energy available for photosynthesis and by the adjustment of physiological processes due to signaling pathways starting from photoreceptors. The first is unlikely due to the small value of the increase in PAR (Figure 1), which suggests the role of regulatory systems. Currently, it is known that all plants have receptors for red and far-red light—phytochromes (phy)—blue and UV-A light—cryptochromes, phototropins 
and members of the Zeitlupe family (cry, phot, ZTL, FKF1 and LKP2) - as well as UV-B light-UV RESISTANCE LOCUS 8 (UVR8) [30,31]. Changes in the intensity of light in these wavelength regions lead to morphometric and physiological rearrangements, which is known as photomorphogenesis. Due to the intersection of signaling pathways from different photoreceptors, the amplification of light at different wavelengths can lead to similar results. Thus, both blue and red light, through the pathways of phototropins and phytochromes, cause leaf expansion [32,33], which was shown in plants grown under a photoconversion coating (Figure 2). During the regulation of photosynthetic processes, red light through the signaling pathways of phytochromes activates chlorophyll synthesis and regulates the number of chloroplasts [34] and blue light through the phototropin cascade affects the position of chloroplasts in the cell [35]. In sum, this can also contribute to the stimulation of photosynthesis observed in our experiments (Figure 3). For other effects, the ratio of the intensity of the luminous flux at certain wavelengths plays a decisive role. Thus, a low ratio of red $(660 \mathrm{~nm}$, an activated form of phytochrome) to far-red (730 nm, an inactivated form of phytochrome) light promotes increased NADPH oxidase-induced generation of $\mathrm{H}_{2} \mathrm{O}_{2}$, which can damage components of the photosynthetic apparatus [36-38]. At a high red/far-red light ratio, on the contrary, the level of $\mathrm{H}_{2} \mathrm{O}_{2}$ decreases due to an increase in antioxidant protection as a result of the induction of the transcriptional activity of some genes of antioxidant enzymes [39]. The photoconversion coatings used in our experiments have a photoluminescence maximum at $630 \mathrm{~nm}$ [10], which leads to an increase in the red/far-red light ratio. This causes a decrease in the content of $\mathrm{H}_{2} \mathrm{O}_{2}$ in plants grown using photoconversion coatings (Figure 7).

Partial exclusion of UV radiation from the spectrum can also have a significant biological effect. Unlike UV-B (280-315 nm) and UV-C (100-280 nm) radiation, the UV-A (315-400 nm) used in our experiments is usually not associated with a pronounced inhibitory effect on morphometric parameters, but it has traditionally been considered to be damaging for photosynthesis [40,41]. The damaging effect of UV-A on the catalytic Mn cluster of a water-oxidizing complex, protein D1 and D2 subunits of the PSII reaction center, QA and QB binding sites and Rubisco has been described [41-45]. This corresponds to lower values of indicators of both light-driven and light-independent reactions of photosynthesis, recorded in our experiments in control plants that received a greater amount of UV-A radiation (Figure 3). An increase in the level of ROS, which occurs mainly due to the work of cytoplasmic NADPH oxidase, has been shown to be one of the key mechanisms of action of UV radiation, including the UV-A component $[44,46,47]$. Thus, under conditions of a decrease in the UV-A spectrum, a decrease in the activity of NADPH oxidase contributes to a decrease in the content of $\mathrm{H}_{2} \mathrm{O}_{2}$ in plants grown under a photoconversion coating (Figure 7), which is in line with other studies with a decrease in the UV-A spectrum [47].

A decrease in the ROS level can also explain another effect found in plants grown under the photoconversion coating - a decrease in resistance to heat stress (Figure 4). It is now well known that ROS and, in particular, their most long-lived form, $\mathrm{H}_{2} \mathrm{O}_{2}$, not only causes damage to macromolecules, but also performs signaling functions $[20,48,49]$. $\mathrm{H}_{2} \mathrm{O}_{2}$ is involved in switching between modes of increased productivity and increased resistance due to regulation at the physiological and genetic levels [20,50]. One of the most significant mechanisms of such a switch is the redistribution of energy resources between the processes of biosynthesis-productivity and the antioxidant system protection. The reduced capacity of the antioxidant system may contribute to the reduced resistance of plants grown under a photoconversion film to heat stress found in our experiments (Figure 4). It should also be noted that $\mathrm{H}_{2} \mathrm{O}_{2}$ is a component of distant stress signals. Longdistance electrical signals are jointly propagating and mutually reinforcing waves of ROS, $\mathrm{Ca}^{2+}$ and electric potential [16,51]. In our previous work, we showed that in plants grown under a photoconversion coating, the amplitude and the conductivity of long-distance electrical signals decreases [10].

The spread of ES causes a rearrangement of physiological processes, which contributes to the formation of resistance (systemic acquired acclimation, SAA) to stressors, including 
heat stress [17,18,22]. Functional response is formed due to shifts in ionic concentrations (primarily $\mathrm{Ca}^{2+}$ and $\mathrm{H}^{+}$) accompanying signal propagation $[18,52,53]$. These functional responses include signal-induced inhibition of photosynthesis (Figure 5), which results in reduced ROS generation at ETC and thus reduced damage to the photosynthetic apparatus under suboptimal conditions. Signal-induced reduction in transpiration (Figure 5) prevents excess water loss and plant wilting. In addition, it is necessary to emphasize the recently demonstrated [54] ability of ES to increase the expression of the heat shock factor (HSF) families which promote the synthesis of heat shock proteins (HSP), which are directly involved in heat stress protection. The protective effect of local heating-induced ES against tomato plants subjected to heat stress is also shown in our experiments (Figure 6). One of the key factors in increasing resistance as a result of ES, a temporarily inhibited photosynthesis, occurs both directly and indirectly, through hormonal shifts that contribute to stomatal closure and a decrease in $\mathrm{CO}_{2}$ availability [55-58]. The absence of a significant effect on transpiration, by which the stomata openness is judged (Figure 6), suggests the development of the effect in tomato plants mainly along the path of direct influence on photosynthetic processes. Since the amplitude of ion shifts, as a rule, correlates with the amplitude of ES [23,59], the weakening of signal-induced resistance in plants grown using photoconversion technologies (Figure 6) can be explained by the suppression of stress signals.

\section{Conclusions}

Photoconversion coatings for greenhouses increase the size of tomato plants and activate the process of photosynthesis. Due to the change in the quality of light and a related possible decrease in the content of ROS in tissues in such plants, the development program is probably shifted towards productivity to the detriment of protective functions. Plants grown using photoconversion technologies have reduced resistance to heat stress as well as less pronounced regulation of resistance by long-distance electrical signals. Thus, when using photoconversion technologies, it is necessary to pay increased attention to maintaining stable conditions during plant cultivation. The development of specific methods for improving practical greenhouse plant production requires additional experimental research, including with various options for lighting sources that closely simulate both sunlight and light sources traditionally used in greenhouses.

Supplementary Materials: The following are available online at https:/ /www.mdpi.com/article/10 .3390/plants11020229/s1, Figure S1: Photoluminescence spectrum of a fluoropolymer film containing fluorophores and gold nanoparticles (solid line) and without photoconverting components (dotted line), obtained using a xenon reference light source.

Author Contributions: Conceptualization, M.G. and V.V.; methodology, M.G., V.S. and V.V.; investigation, M.G., E.G., A.G., E.B., M.L. and A.V.S.; data curation, M.G. and V.V.; writing-original draft preparation, M.G.; writing-review and editing, S.V.G. and V.V.; visualization, M.G., E.B. and M.L.; project administration, V.V.; funding acquisition, S.V.G. and V.V. All authors have read and agreed to the published version of the manuscript.

Funding: The investigation was funded by the Ministry of Science and Higher Education of the Russian Federation for large scientific projects in priority areas of scientific and technological development (contract no. 075-15-2020-774).

Data Availability Statement: Data is contained within the article and supplementary material.

Acknowledgments: We would like to express our gratitude to A. Savikin for his help in the spectrum registration.

Conflicts of Interest: The authors declare no conflict of interest. 


\section{References}

1. Li, X.; Lu, W.; Hu, G.; Wang, X.C.; Zhang, Y.; Sun, G.X.; Fang, Z. Effects of light-emitting diode supplementary lighting on the winter growth of greenhouse plants in the Yangtze River Delta of China. Bot. Stud. 2016, 57, 2. [CrossRef] [PubMed]

2. Berkovich, Y.; Konovalova, I.; Erokhin, A.; Smolyanina, S.; Smolyanin, V.; Yakovleva, O.; Tarakanov, I.; Ivanov, T. LED lighting optimization as applied to a vitamin space plant growth facility. Life Sci. Space Res. 2019, 20, 93-100. [CrossRef] [PubMed]

3. Prikupets, L.B.; Boos, G.V.G.V.; Terekhov, V.G.; Tarakanov, I.G. Optimisation of Lighting Parameters of Irradiation in Light Culture of Lettuce Plants Using LED Emitters. Light Eng. 2019, 27, 43-54. [CrossRef]

4. Palmitessa, O.; Prinzenberg, A.; Kaiser, E.; Heuvelink, E. LED and HPS Supplementary Light Differentially Affect Gas Exchange in Tomato Leaves. Plants 2021, 10, 810. [CrossRef] [PubMed]

5. Sobczak, A.; Sujkowska-Rybkowska, M.; Gajc-Wolska, J.; Kowalczyk, W.; Borucki, W.; Kalaji, H.M.; Kowalczyk, K. Photosynthetic Efficiency and Anatomical Structure of Pepper Leaf (Capsicum annuum L.) Transplants Grown under High-Pressure Sodium (HPS) and Light-Emitting Diode (LED) Supplementary Lighting Systems. Plants 2021, 10, 1975. [CrossRef]

6. Dannehl, D.; Schwend, T.; Veit, D.; Schmidt, U. Increase of Yield, Lycopene, and Lutein Content in Tomatoes Grown Under Continuous PAR Spectrum LED Lighting. Front. Plant Sci. 2021, 12, 299. [CrossRef] [PubMed]

7. Iddio, E.; Wang, L.; Thomas, Y.; McMorrow, G.; Denzer, A. Energy efficient operation and modeling for greenhouses: A literature review. Renew. Sustain. Energy Rev. 2020, 117, 109480. [CrossRef]

8. Krizek, D.T.; Clark, H.D.; Mirecki, R.M. Spectral Properties of Selected UV-blocking and UV-transmitting Covering Materials with Application for Production of High-value Crops in High Tunnelst. Photochem. Photobiol. 2005, 81, 1047-1051. [CrossRef]

9. Liu, C.-H.; Ay, C.; Kan, J.-C.; Lee, M.-T. The Effect of Radiative Cooling on Reducing the Temperature of Greenhouses. Materials 2018, 11, 1166. [CrossRef]

10. Gudkov, S.V.; Simakin, A.V.; Bunkin, N.F.; Shafeev, G.A.; Astashev, M.E.; Glinushkin, A.P.; Grinberg, M.A.; Vodeneev, V.A. Development and application of photoconversion fluoropolymer films for greenhouses located at high or polar latitudes. $J$. Photochem. Photobiol. B Biol. 2020, 213, 112056. [CrossRef]

11. Parrish, C.H., II; Hebert, D.; Jackson, A.; Ramasamy, K.; McDaniel, H.; Giacomelli, G.A.; Bergren, M.R. Optimizing spectral quality with quantum dots to enhance crop yield in controlled environments. Commun. Biol. 2021, 4, 124. [CrossRef] [PubMed]

12. Murakami, K.; Cui, H.; Kiyota, M.; Aiga, I.; Yamane, T. Control of Plant Growth by Covering Materials for Greenhouses which Alter the Spectral Distribution of Transmitted Light. Acta Hortic. 1997, 435, 123-130. [CrossRef]

13. Hemming, S.; van Os, E.A.; Hemming, J.; Dieleman, J.A. The Effect of New Developed Fluorescent Greenhouse Films on the Growth of Fragaria $\times$ ananassa 'Elsanta'. Eur. J. Hortic. Sci. 2006, 71, 145-154.

14. Ivanyuk, V.V.; Shkirin, A.V.; Belosludtsev, K.N.; Dubinin, M.V.; Kozlov, V.A.; Bunkin, N.F.; Dorokhov, A.S.; Gudkov, S.V. Influence of Fluoropolymer Film Modified with Nanoscale Photoluminophor on Growth and Development of Plants. Front. Phys. 2020, 8, 616040. [CrossRef]

15. Yoon, H.; Kang, J.; Kang, W.; Son, J. Subtle changes in solar radiation under a green-to-red conversion film affect the photosynthetic performance and chlorophyll fluorescence of sweet pepper. Photosynthetica 2020, 58, 1107-1115. [CrossRef]

16. Choi, W.-G.; Hilleary, R.; Swanson, S.J.; Kim, S.-H.; Gilroy, S. Rapid, Long-Distance Electrical and Calcium Signaling in Plants. Annu. Rev. Plant Biol. 2016, 67, 287-307. [CrossRef]

17. Szechynska-Hebda, M.; Lewandowska, M.; Karpiński, S. Electrical Signaling, Photosynthesis and Systemic Acquired Acclimation. Front. Physiol. 2017, 8, 684. [CrossRef]

18. Sukhov, V.; Sukhova, E.; Vodeneev, V. Long-distance electrical signals as a link between the local action of stressors and the systemic physiological responses in higher plants. Prog. Biophys. Mol. Biol. 2019, 146, 63-84. [CrossRef] [PubMed]

19. Verma, V.; Ravindran, P.; Kumar, P.P. Plant hormone-mediated regulation of stress responses. BMC Plant Biol. 2016, 16, 1-10. [CrossRef]

20. Choudhury, F.K.; Rivero, R.M.; Blumwald, E.; Mittler, R. Reactive oxygen species, abiotic stress and stress combination. Plant J. 2017, 90, 856-867. [CrossRef]

21. Mudrilov, M.; Ladeynova, M.; Grinberg, M.; Balalaeva, I.; Vodeneev, V. Electrical Signaling of Plants under Abiotic Stressors: Transmission of Stimulus-Specific Information. Int. J. Mol. Sci. 2021, 22, 10715. [CrossRef]

22. Fromm, J.; Lautner, S. Electrical signals and their physiological significance in plants. Plant Cell Environ. 2006, 30, $249-257$. [CrossRef]

23. Sukhov, V. Electrical signals as mechanism of photosynthesis regulation in plants. Photosynth. Res. 2016, 130, 373-387. [CrossRef]

24. Tucker, E.B.; Lee, M.; Alli, S.; Sookhdeo, V.; Wada, M.; Imaizumi, T.; Kasahara, M.; Hepler, P.K. UV-A Induces Two Calcium Waves in Physcomitrella patens. Plant Cell Physiol. 2005, 46, 1226-1236. [CrossRef]

25. Marten, I.; Deeken, R.; Hedrich, R.; Roelfsema, R. Light-induced modification of plant plasma membrane ion transport. Plant Biol. 2010, 12, 64-79. [CrossRef]

26. Moan, J. Visible light and UV radiation. In Radiation at Home, Outdoors and in the Workplace; Brune, A., Hellborg, R., Persson, B.R.R., Pääkkönen, R., Eds.; Scandinavian Science Publisher: Oslo, Norway, 2013; Volume 2001, pp. $69-85$.

27. Maxwell, K.; Johnson, G.N. Chlorophyll fluorescence-A practical guide. J. Exp. Bot. 2000, 51, 659-668. [CrossRef] [PubMed]

28. Klughammer, C.; Schreiber, U. Saturation pulse method for assessment of energy conversion in PS I. Planta 1994, 192, 261-268. [CrossRef] 
29. Hlavinka, J.; Nauš, J.; Špudová, M. Anthocyanin contribution to chlorophyll meter readings and its correction. Photosynth. Res. 2013, 118, 277-285. [CrossRef] [PubMed]

30. Kami, C.; Lorrain, S.; Hornitschek, P.; Fankhauser, C. Light-Regulated Plant Growth and Development. Curr. Top. Dev. Biol. 2010 91, 29-66.

31. Liang, T.; Yang, Y.; Liu, H. Signal transduction mediated by the plant UV-B photoreceptor UVR8. New Phytol. 2018, 221, 1247-1252. [CrossRef]

32. Sakamoto, K.; Briggs, W.R. Cellular and Subcellular Localization of Phototropin 1. Plant Cell 2002, 14, 1723-1735. [CrossRef]

33. Franklin, K.A.; Praekelt, U.; Stoddart, W.M.; Billingham, O.E.; Halliday, K.; Whitelam, G.C. Phytochromes B, D, and E Act Redundantly to Control Multiple Physiological Responses in Arabidopsis. Plant Physiol. 2003, 131, 1340-1346. [CrossRef]

34. Zhao, J.; Zhou, J.-J.; Wang, Y.-Y.; Gu, J.-W.; Xie, X.-Z. Positive Regulation of Phytochrome B on Chlorophyll Biosynthesis and Chloroplast Development in Rice. Rice Sci. 2013, 20, 243-248. [CrossRef]

35. Gotoh, E.; Suetsugu, N.; Yamori, W.; Ishishita, K.; Kiyabu, R.; Fukuda, M.; Higa, T.; Shirouchi, B.; Wada, M. Chloroplast Accumulation Response Enhances Leaf Photosynthesis and Plant Biomass Production. Plant Physiol. 2018, 178, 1358-1369. [CrossRef] [PubMed]

36. Oukarroum, A.; Bussotti, F.; Goltsev, V.; Kalaji, H. Correlation between reactive oxygen species production and photochemistry of photosystems I and II in Lemna gibba L. plants under salt stress. Environ. Exp. Bot. 2015, 109, 80-88. [CrossRef]

37. Kreslavski, V.D.; Los, D.A.; Schmitt, F.-J.; Zharmukhamedov, S.K.; Kuznetsov, V.V.; Allakhverdiev, S.I. The impact of the phytochromes on photosynthetic processes. Biochim. Biophys. Acta 2018, 1859, 400-408. [CrossRef] [PubMed]

38. Wang, F.; Wu, N.; Zhang, L.; Ahammed, G.J.; Chen, X.; Xiang, X.; Zhou, J.; Xia, X.; Shi, K.; Yu, J.; et al. Light Signaling-Dependent Regulation of Photoinhibition and Photoprotection in Tomato. Plant Physiol. 2018, 176, 1311-1326. [CrossRef] [PubMed]

39. Kreslavski, V.D.; Shirshikova, G.N.; Lyubimov, V.Y.; Shmarev, A.N.; Boutanaev, A.M.; Kosobryukhov, A.A.; Schmitt, F.-J.; Friedrich, T.; Allakhverdiev, S.I. Effect of preillumination with red light on photosynthetic parameters and oxidant-/antioxidant balance in Arabidopsis thaliana in response to UV-A. J. Photochem. Photobiol. B Biol. 2013, 127, 229-236. [CrossRef]

40. Nawkar, G.M.; Maibam, P.; Park, J.H.; Sahi, V.P.; Lee, S.Y.; Kang, C.H. UV-Induced Cell Death in Plants. Int. J. Mol. Sci. 2013, 14, 1608-1628. [CrossRef]

41. Verdaguer, D.; Jansen, M.A.; Llorens, L.; Morales, L.O.; Neugart, S. UV-A radiation effects on higher plants: Exploring the known unknown. Plant Sci. 2017, 255, 72-81. [CrossRef]

42. Christopher, D.A.; Mullet, J.E. Separate Photosensory Pathways Co-Regulate Blue Light/Ultraviolet-A-Activated psbD-psbC Transcription and Light-Induced D2 and CP43 Degradation in Barley (Hordeum vulgare) Chloroplasts. Plant Physiol. 1994, 104, 1119-1129. [CrossRef]

43. Vass, I.; Turcsányi, E.; Touloupakis, E.; Ghanotakis, A.D.; Petrouleas, V.; Touloupakis, E. The Mechanism of UV-A RadiationInduced Inhibition of Photosystem II Electron Transport Studied by EPR and Chlorophyll Fluorescence. Biochemistry 2002, 41, 10200-10208. [CrossRef]

44. Nayak, L.; Biswal, B.; Ramaswamy, N.; Iyer, R.; Nair, J.; Biswal, U. Ultraviolet-A induced changes in photosystem II of thylakoids: Effects of senescence and high growth temperature. J. Photochem. Photobiol. B Biol. 2003, 70, 59-65. [CrossRef]

45. Tyystjärvi, E. Photoinhibition of Photosystem II and photodamage of the oxygen evolving manganese cluster. Coord. Chem. Rev. 2008, 252, 361-376. [CrossRef]

46. Jia, L.; Tian, J.; Wei, S.; Zhang, X.; Xu, X.; Shen, Z.; Shen, W.; Cui, J. Hydrogen gas mediates ascorbic acid accumulation and antioxidant system enhancement in soybean sprouts under UV-A irradiation. Sci. Rep. 2017, 7, 16366. [CrossRef]

47. Zhang, J.; Chen, C.; Zhang, D.; Li, H.; Li, P.; Ma, F. Reactive oxygen species produced via plasma membrane NADPH oxidase regulate anthocyanin synthesis in apple peel. Planta 2014, 240, 1023-1035. [CrossRef] [PubMed]

48. Waszczak, C.; Carmody, M.; Kangasjärvi, J. Reactive Oxygen Species in Plant Signaling. Annu. Rev. Plant Biol. 2018, 69, 209-236. [CrossRef] [PubMed]

49. Gudkov, S.V.; Grinberg, M.A.; Sukhov, V.; Vodeneev, V. Effect of ionizing radiation on physiological and molecular processes in plants. J. Environ. Radioact. 2019, 202, 8-24. [CrossRef] [PubMed]

50. Borisova-Mubarakshina, M.M.; Vetoshkina, D.V.; Ivanov, B.N. Antioxidant and signaling functions of the plastoquinone pool in higher plants. Physiol. Plant. 2019, 166, 181-198. [CrossRef]

51. Vodeneev, V.; Akinchits, E.; Sukhov, V. Variation potential in higher plants: Mechanisms of generation and propagation. Plant Signal. Behav. 2015, 10, e1057365. [CrossRef] [PubMed]

52. Grams, T.; Lautner, S.; Felle, H.H.; Matyssek, R.; Fromm, J. Heat-induced electrical signals affect cytoplasmic and apoplastic pH as well as photosynthesis during propagation through the maize leaf. Plant Cell Environ. 2009, 32, 319-326. [CrossRef] [PubMed]

53. Bulychev, A.A.; Komarova, A.V. Long-distance signal transmission and regulation of photosynthesis in characean cells. Biochemistry 2014, 79, 273-281. [CrossRef] [PubMed]

54. Zandalinas, S.I.; Fichman, Y.; Devireddy, A.R.; Sengupta, S.; Azad, R.K.; Mittler, R. Systemic signaling during abiotic stress combination in plants. Proc. Natl. Acad. Sci. USA 2020, 117, 13810-13820. [CrossRef] [PubMed]

55. Krausko, M.; Perutka, Z.; Šebela, M.; Šamajová, O.; Šamaj, J.; Novak, O.; Pavlovič, A. The role of electrical and jasmonate signalling in the recognition of captured prey in the carnivorous sundew plant Drosera capensis. New Phytol. 2017, 213, 1818-1835. [CrossRef] 
56. Vuralhan-Eckert, J.; Lautner, S.; Fromm, J. Effect of simultaneously induced environmental stimuli on electrical signalling and gas exchange in maize plants. J. Plant Physiol. 2018, 223, 32-36. [CrossRef]

57. Ladeynova, M.; Mudrilov, M.; Berezina, E.; Kior, D.; Grinberg, M.; Brilkina, A.; Sukhov, V.; Vodeneev, V. Spatial and Temporal Dynamics of Electrical and Photosynthetic Activity and the Content of Phytohormones Induced by Local Stimulation of Pea Plants. Plants 2020, 9, 1364. [CrossRef]

58. Zandalinas, S.I.; Fritschi, F.B.; Mittler, R. Signal transduction networks during stress combination. J. Exp. Bot. 2020, 71, $1734-1741$. [CrossRef]

59. Grinberg, M.A.; Gudkov, S.V.; Balalaeva, I.V.; Gromova, E.; Sinitsyna, Y.; Sukhov, V.; Vodeneev, V. Effect of chronic $\beta$-radiation on long-distance electrical signals in wheat and their role in adaptation to heat stress. Environ. Exp. Bot. 2021, 184, 104378. [CrossRef] 